\title{
Analisis mitigasi bencana dan kajian geologi ngarai sianok dalam pengembangan konservasi berkelanjutan di geopark nasional ngarai sianok - maninjau, sumatera barat
}

\author{
Ahmad Fadhly $^{1)^{*}}$, Dian Hadiyansyah ${ }^{2)}$ \\ ${ }^{12}$ Sekolah Tinggi Teknologi Industri Padang, Jln. Prof. Dr. Hamka No. 121 Tabing, Padang, Indonesia \\ ahmadfadhly.geo08@yahoo.com*
}

\begin{abstract}
ABSTRAK
Kawasan Ngarai Sianok merupakan objek geologi di dalam deliniasi Geopark Nasional Ngarai Sianok Maninjau, manajemen pengembangan kawasan yang memberikan pengaruh penting berskala regional terhadap konservasi, edukasi, dan peningkatan kesejahteraan masyarakat merupakan bagian dalam konsep geopark. Geopark adalah konsep pemanfaatan berkesinambungan atas sumber daya geodiversity, biodiversity, dan cultural diversity, hal ini teridentifikasi pada saat Geopark Nasional ngarai Sianok -Maninjau ditetapkan menjadi kawasan Geopark Nasional pada tahun 2018,sehingga terbuka bagi penulis untuk dapat menidentifikasi kawasan untuk pembangunan daerah dari sisi ilmu kebumian. Pola pengembangan geopark secara umum tidak terlepas dari konsep konservasi dan edukasi. Dampak selanjutnya adalah tentu saja akan akan memacu tumbuhnya ekonomi kreatif di masyarakat. Sebagai warisan alam, kawasan sumberdaya geologi di banyak tempat teridentifikasi merupakan daerah padat penduduk dan di dalamnya terjadi kegiatan ekonomi. Permasalahan penataan pemukiman warga sekitar tebing Ngarai Sianok dan kota Bukittinggi bukanlah hal yang mudah diselesaikan terkait patahan sumatera di objek Ngarai Sianok dengan konsep kebencanaannya. Tujuan penelitian ini adalah menganalisis informasi geologi, geomorfologi, lingkungan di Ngarai Sianok, menganalisis hubungan tersebut yang menjadi indikator kunci (key-indicator) dalam menentukan daerah potensi Geowisata dengan konsep geopark di Geopark Ngarai Sianok -Maninjau, dan mengembangkan program sadar wisata berbasis keilmuan terkait mitigasi bencana bagi warga yang bermukim di sekitar kawasan Geopark untuk menaikan usaha ekonomi masyarakat dan menerapkan pola konservasi. Metode penelitian dengan melakukan identifikasi lapangan dengan data geologi dan analisis mitigasi dikawasan hingga melakukan observasi data masyarakat terhadap pola mitigasi setempat Tahap penelitian berupa pengambilan data lapangan untuk mengetahui gambaran umum tentang data geologi daerah penelitian, mengobservasi data primer berkaitan data sekunder serta komponen yang akan dikembangkan secara terintegrasi. Penelitian diharapkan dapat dikembangkan dengan baik bagi edukasi terkait mitigasi bencana dengan informasi - informasi.
\end{abstract}

Kata kunci: Geopark, Konservasi, Mitigasi bencana, Geowisata

\section{ABSTRACT}

The Ngarai Sianok area is a geological object in the delineation of the Ngarai Sianok - Maninjau National Geopark, management of regional development that has an important regional-scale influence on conservation, education, and improving people's welfare is part of the geopark concept. Geopark is the concept of sustainable use of geodiversity, biodiversity, and cultural diversity resources, this was identified when the Sianok-Maninjau National Geopark was designated as a National Geopark area in 2018, so it is open for authors to be able to identify areas for regional development from a scientific perspective. earthly. Geopark development patterns in general can not be separated from the concept of conservation and education. The next impact is of course it will spur the growth of the creative economy in society. As a natural heritage, geological resource areas are identified in many places as densely populated areas and in which economic activities occur. The problem of structuring the settlements of residents around the cliffs of the Sianok canyon and the city of Bukittinggi is not an easy matter to solve regarding the Sumatran fault in the Sianok canyon object with the concept of disaster. The purpose of this study is to analyze geological, geomorphological, environmental information in Ngarai Sianok, analyze the relationship which is a key indicator (key-indicator) in determining geotourism potential areas with the concept of geopark in Ngarai Sianok Geopark-Maninjau, and develop a science-based tourism awareness program related to disaster mitigation for residents living around the Geopark area to increase the 
community's economic business and implement conservation patterns. The research method uses field identification with geological data and mitigation analysis in the area to observe community data on local mitigation patterns. The research stage is in the form of field data collection to find out an overview of the geological data of the research area, observing primary data related to secondary data and components that will be developed systematically. integrated. The research is expected to be well developed for education related to disaster mitigation with information.

Keywords: Geopark, Conservation, Disaster Mitigation, Geotourism

diunggah: November 2021, direvisi: Desember 2021, diterima: Desember 2021, dipublikasi: Desember 2021

Copyright (c) 2021 Ahmad Fadhly, Dian Hadiyansyah

This is an open access article under the CC-BY license

\section{PENDAHULUAN}

Geopark Ngarai Sianok Maninjau termasuk ke dalam kawasan Kota Bukittinggi dengan Kabupaten Agam, Provinsi Sumatera Barat. Berdasarkan batas administrasi daerah, Geopark Ngarai Sianok Maninjau masuk ke dalam zona lembahan patahan Sesar Sumatera (Sesar Semangko). Sesar Sumatera adalah sesar yang suatu saat dapat aktif kembali (reaktifasi) yang membuat lembah Ngarai Sianok. Dalam kawasan ini juga terdapat fenomena geologi besar yang terdapat pada Kaldera Maninjau berukuran $34 \mathrm{~km} \mathrm{x} 12 \mathrm{~km}$ yang merupakan sebuah danau dengan volume air mendekati $100 \mathrm{~km}^{3}$ dan tersingkap formasi batuan dan endapan piroklastika hasil erupsi Kaldera Maninjau. Unsur-unsur bukti geologi tersebut menjadi dasar bagi peneliti dalam mengkaji informasi geologi dengan potensi ngarai sianok dengan bentang alamnya tetapi ada juga terkait dengan masalah kebencanaanya, hal ini teridentifikasi pada saat Geopark Ngarai Sianok - Maninjau ditetapkan menjadi kawasan Geopark Nasional pada tahun 2018, sehingga terbuka bagi penulis untuk mengidentifikasi dan mengevaluasi dampak yang ditimbulkan terhadap ruang dan kegiatan manusia sekitar, Mengembangkan program sadar wisata dan lingkungan bagi warga yang bermukim di sekitar kawasan Geopark.

\section{METODE}

Metode penelitian yang dilakukan terdiri dari beberapa metode meliputi pengumpulan data sekunder berupa geologi regional dan peta kawasan geopark, pengumpulan data primer berupa data kegiatan lapangan, analisis batuan untuk mengolah data lapangan dan data geomorfologi dan geologi. Tahap pendahuluan sebelum melakukan penelitian dan pengambilan data lapangan, meliputi studi regional daerah penelitian untuk mengetahui gambaran umum tentang data geologi daerah penelitian, sehingga kegiatan lapangan sangat membantu dalam mendukung kompilasi data sekunder sebagai dasar utama dalam penelitian.

Dalam pelaksanaan penelitian ini penulis mengacu pada Peta Geologi Regional Lembar Padang skala $1: 250.000$,. Peta dasar yang digunakan untuk orientasi lapangan adalah Peta Rupa Bumi Indonesia skala 1 : 50.000 yang diterbitkan oleh lembaga pemerintah yang bertanggung jawab dalam bidang geospasial. Penelitian ini mengacu pada prinsip bidang geologi - geomorfologi dan relevansi dari beberapa cabang terapan ilmu lain untuk mengarahkan dan memfokuskan penelitian ini untuk menganalisis konsep mitigasi kawasan dengan edukasi data penelitian dikemas dengan aktifitas local dalam pengembangan daerah. 


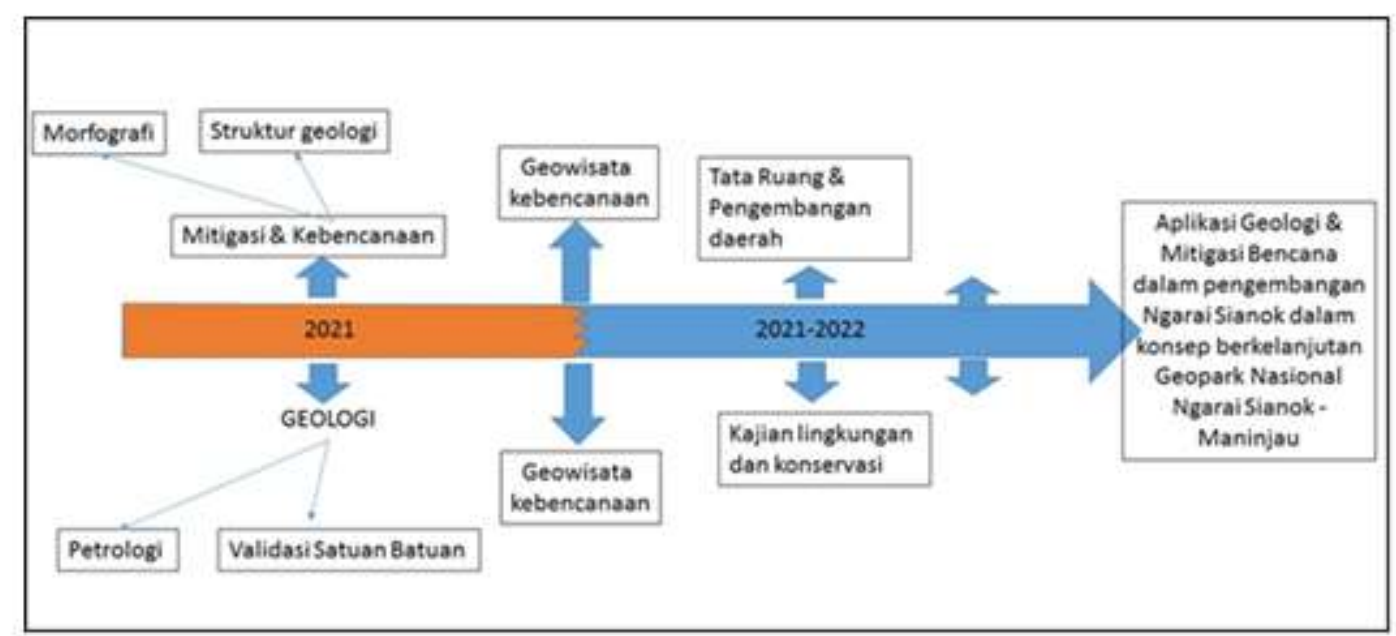

Gambar 1. Kenampakan map view analisis citra satelit sianok

\section{HASIL DAN PEMBAHASAN}

\section{Geomorfologi daerah penelitian}

Dalam menentukan batas- batas satuan geomorfologi, deliniasi relief digunakan sebagai perameter utama yang dibantu dengan menggunakan pendekatan terhadap unsur morfografi, pola pengaliran dan morfometri. Menurut Van Zuidam (1985), perbedaan titik ketinggian diukur dari permukaan laut, karena permukaan laut dianggap sebagai bidang yang memilki angka ketinggian nol [5]. Pentingnya pengenalan perbedaan ketinggian adalah untuk menyatakan keadaan morfografi dan morfogenetik suatu bentuklahan, seperti perbukitan, pegunungan atau dataran.

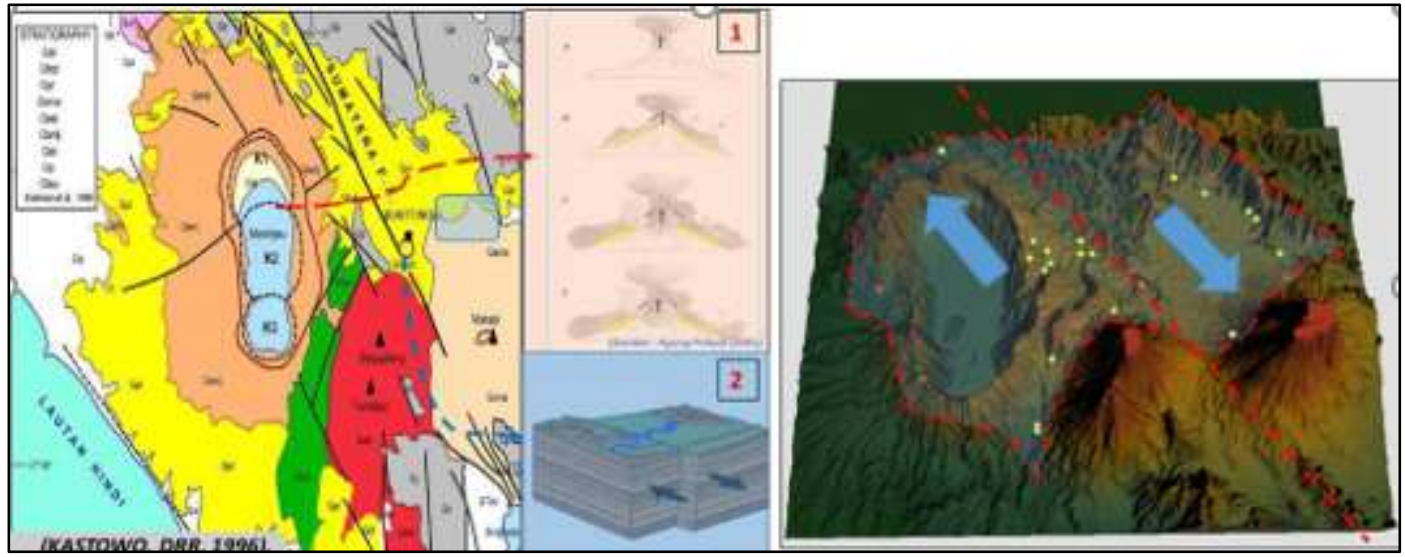

Gambar 2. Kenampakan map view analisis citra satelit sianok

Berdasarkan kemiringan lerengnya, satuan geomorfologi daerah penelitian terbagi menjadi tiga satuan, yaitu:

\section{Satuan Bentang Alam Dataran}

Satuan bentang alam dataran menyebar relatif pada bagian Barat (dataran pesisir pantai) dan dataran-dataran dari lembah-lembah depresi dengan ketinggian $0-200 \mathrm{dpl}$. Sungai-sungai yang mengalir ditempati oleh jenis bentang alam aluvium, Batuan produk gunung api serta batuan hasil rombakan berupa teras sungai, dengan pola aliran relatif berpola dendritik.

\section{Satuan Bentang Alam Perbukitan}

Satuan bentang alam perbukitan ini menempati 25,6 \% (995 Km2) dari luas daerah penelitian dengan ketinggian 200-1.000 dpl. Sebagian besar merupakan bagian dari jalur bukit barisan yang memanjang dari Baratlaut-Tenggara. Satuan bentang alam 
perbukitan ini terdiri dari perbukitan memanjang dan daerah perbukitan bergelombang. Satuan ini umumnya ditempati oleh batuan yang berumur Paleozoikum, Mesozoikum dan batuan Tersier, dengan pola aliran sungai berpola subdendritik-dendritik.

\section{Satuan Bentang Alam Gunungapi Strato}

Satuan bentang alam gunungapi strato dengan ketinggian $>1.000$ meter dpl, menyebar pada bagian selatan daerah penelitian.

Tabel 1. Hubungan ketinggian absolut dengan morfografi

\begin{tabular}{|c|c|c|c|c|c|c|c|c|c|}
\hline \multirow{3}{*}{$\begin{array}{c}\text { Satuan } \\
\text { Geomorfologi }\end{array}$} & \multicolumn{9}{|c|}{$\begin{array}{c}\text { Karakteristik } \\
\text { Umum }\end{array}$} \\
\hline & \multicolumn{4}{|c|}{ Morfografi } & \multicolumn{2}{|c|}{ Morfometri } & \multicolumn{2}{|c|}{ Morfogenetik } & \multirow[b]{2}{*}{$\begin{array}{l}\text { Material } \\
\text { Penyusun }\end{array}$} \\
\hline & $\begin{array}{l}\text { Warna } \\
\text { Simbol }\end{array}$ & $\begin{array}{l}\text { Bentuk } \\
\text { Lahan }\end{array}$ & $\begin{array}{l}\text { Bentuk } \\
\text { Lembah }\end{array}$ & $\begin{array}{c}\text { Pola } \\
\text { Pengaliran }\end{array}$ & $\begin{array}{c}\text { Ketinggia } \\
\mathrm{n}(\mathrm{m})\end{array}$ & $\begin{array}{l}\text { Kemiri } \\
\text { ngan } \\
\text { Lereng } \\
\left({ }^{\circ}\right)\end{array}$ & Endogen & $\begin{array}{l}\text { Eksog } \\
\text { en }\end{array}$ & \\
\hline $\begin{array}{l}\text { Pedataran } \\
\text { Aluvium }\end{array}$ & & Pedataran & $\mathrm{U}$ & $\begin{array}{l}\text { Anasto } \\
\text { matik } \\
\text { Subpar } \\
\text { alel } \\
\end{array}$ & $100-150$ & $0-2$ & & Erosi & Aluvium \\
\hline Perbukitan & & Perbukitan & $\mathrm{U}-\mathrm{V}$ & $\begin{array}{l}\text { subden } \\
\text { dritik }\end{array}$ & $200-290$ & $8-12$ & Tektonik & Erosi & Tuf \\
\hline $\begin{array}{c}\text { Satuan Bentang Alam } \\
\text { Gunungapi Strato }\end{array}$ & & $\begin{array}{l}\text { Perbukitan - } \\
\text { Pegunungan }\end{array}$ & V & $\begin{array}{l}\text { Subden } \\
\text { dritik } \\
\text { Subpar } \\
\text { alel }\end{array}$ & $250-816$ & $20-35$ & Vulkanik & Erosi & Andesit \\
\hline
\end{tabular}

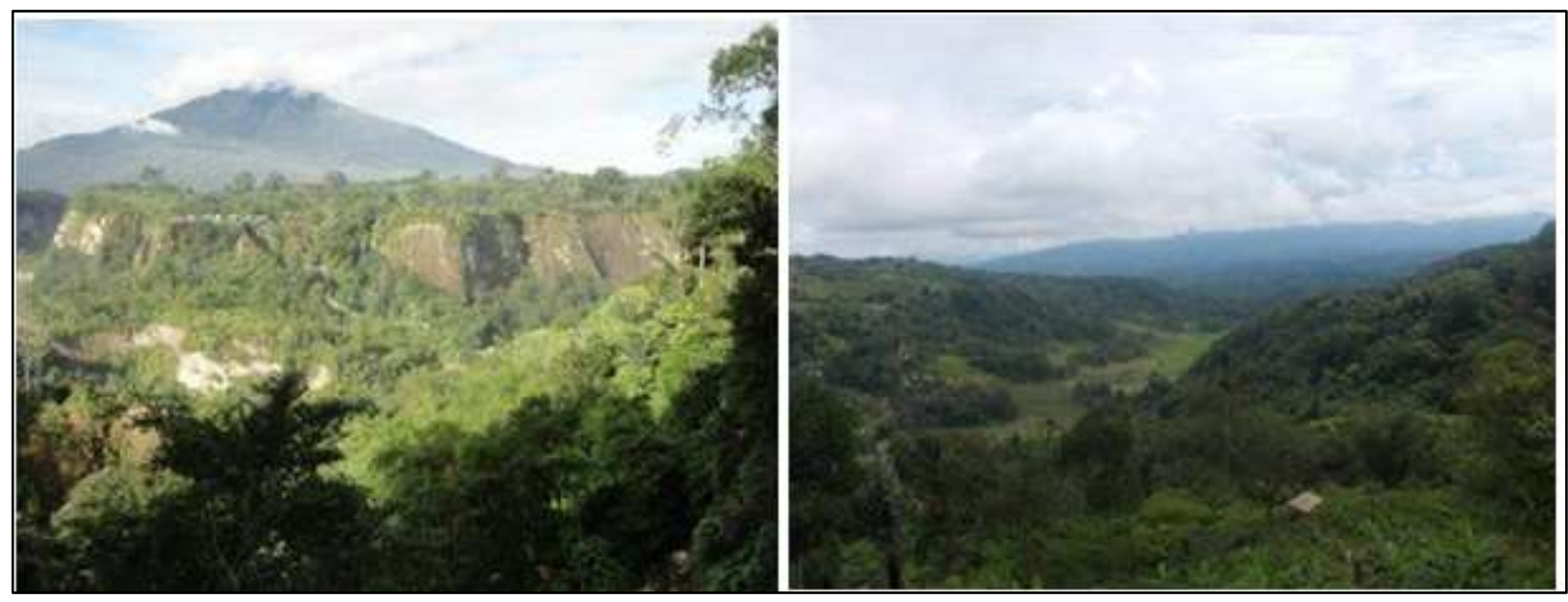

Gambar 3. Satuan geomorfologi segmen sianok

\section{Stratigrafi area lokal}

Secara stratigrafi area lokal, Ngarai Sianok mempunyai siklus endapan tuf dua kali dengan dibatasi oleh aliran sungai atau endapan fluvial vulcanik yang membawa endapan channel berupa batuan konglomerat dari komponen fragmen batuaandesit, obsidian, tuf, dan fosil kayu (charcoal). Ketebalan atau ketinggian Lembah Ngarai mencapai 900 meteran. Hal ini tampak pada gambar. Pada gambar 4 tampak paremeter hanya berada di sekitar aliran Sungai Sianok sementara ketebalan tuf masih lebih jauh di atasnya. Longsoran umum terjadi pada bagian tepi lembah oleh karena proses tektonik, berat jenis tuf, kemiringan, dan proses pengikisan oleh air hujan. Longsoran ini yang membawa tuf terangkut dan tertransportasi melalui aliran Sungai Sianok. Pada bagian lembah lainnya, terdapat rekahan-rekahan sebelum terjadinya longsoran atau disebut calon graben, bagian yang mengalami rekahan dan sesar normal lokal. Nantinya, calon graben ini akan jatuh. Aliran Sungai Sianok atau erosional surface ini akan membawa longsoran tuf bermuara ke Samudera Hindia. Yang membawa 
jauh longsoran tuf ini kearah selatan Bukittinggi. Gambar 4 menampakkan perlapisan satuan tuf maninjau. Dari singkapan ini membuktikannya adanya pengaruh transportasi sedimen yang dibawa angin dan terendapkan di area ini.
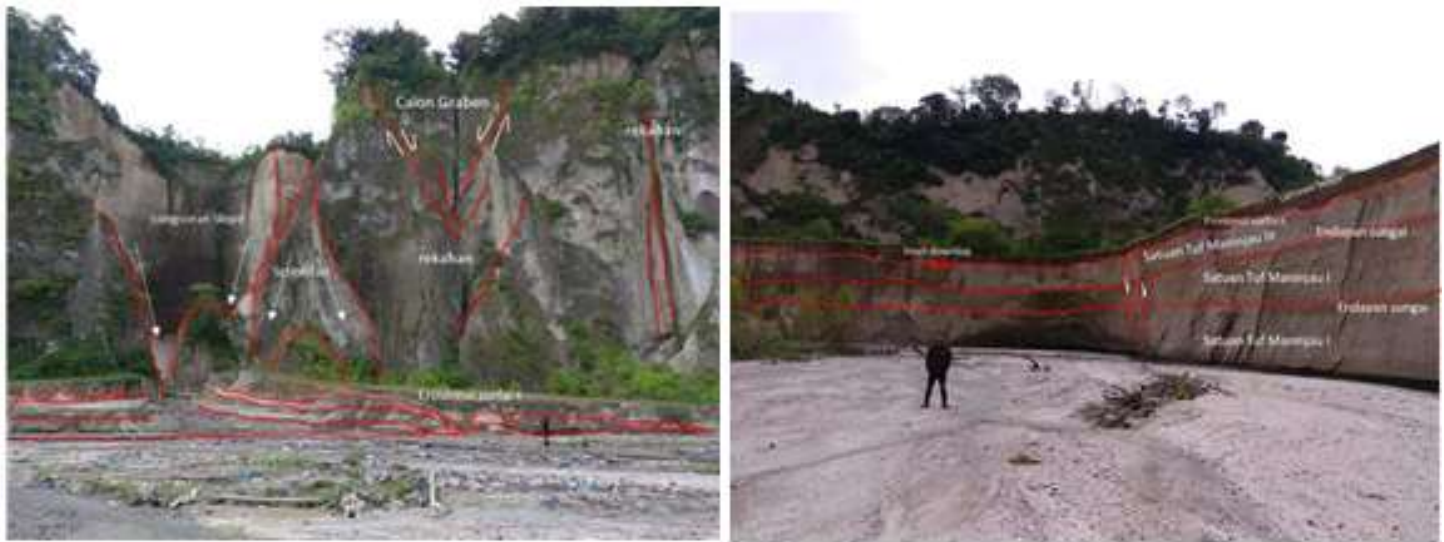

Gambar 4. Singkapan lembah ngarai sianok yang menampakan longsoran

Gambar 5, menunjukkan adanya fosil kayu (charcoal) yang terbawa oleh fluida di bantaran Sungai Sianok. Yang kemudian ikut bercampur dengan tuf dan komponen kerikil batuan sedimen lainnya. Bisa jadi fosil kayu ini terbakar oleh panasnya tuf saat terjadi proses pengendapan di daerah ini sehingga fosil kayu menghitam. Gambar 5 juga memperlihatkan terdapatnya pencampuran antara tuf sebagai semen dan kerikil-kerikil di endapan sungai. Komponen kerikil ini terdiri dari batupasir dan batutuf itu sendiri.


Gambar 5 a. Sisipan fosil kayu dan campuran litologi tuf, sementasi tuf, dan kerikil batuan sedimen

Gambar 5 b. Sketsa dan grafik log singkapan lembah 


\section{Kebijakan dan strategi mitigasi bencana dengan bergeowisata}

Berbagai kebijakan yang perlu ditempuh dalam mitigasi bencana antara lain :

1. Dalam setiap upaya mitigasi bencana perlu membangun persepsi yang sama bagi semua pihak baik jajaran aparat pemerintah maupun segenap unsur masyarakat yang ketentuan langkahnya diatur dalam pedoman umum, petunjuk pelaksanaan dan prosedur tetap yang dikeluarkan oleh instansi yang bersangkutan sesuai dengan bidang tugas unit masing-masing.

2. Pelaksanaan mitigasi bencana dilaksanakan secara terpadu terkoordinir yang melibatkan seluruh potensi pemerintah dan masyarakat.

3. Upaya preventif harus diutamakan agar kerusakan dan korban jiwa dapat diminimalkan

4. Penggalangan kekuatan melalui kerjasama dengan semua pihak, melalui pemberdayaan masyarakat

\section{Strategi}

Untuk melaksanakan kebijakan dikembangkan beberapa strategi sebagai berikut:

Pemetaan.

Langkah pertama dalam strategi mitigasi ialah melakukan pemetaan daerah rawan bencana.

1. Pemantauan.

Dengan mengetahui tingkat kerawanan secara dini, maka dapat dilakukan antisipasi jika sewaktu- waktu terjadi bencana, sehingga akan dengan mudah melakukan penyelamatan.

2. Penyebaran informasi

Penyebaran informasi dilakukan antara lain dengan cara: memberikan poster dan leaflet kepada Pemerintah Kabupaten/Kota yang rawan bencana, tentang tata cara mengenali, mencegah dan penanganan bencana.

3. Sosialisasi dan Penyuluhan

Sosialisasi dan penyuluhan tentang segala aspek kebencanaan kepada petugas pelaksana dan masyarakat bertujuan meningkatkan kewaspadaan dan kesiapan menghadapi bencana jika sewaktu- waktu terjadi.

4. Pelatihan/Pendidikan

Pelatihan difokuskan kepada tata cara pengungsian dan penyelamatan jika terjadi bencana.

5. Peringatan Dini

Peringatan dini dimaksudkan untuk memberitahukan tingkat kegiatan hasil pengamatan secara kontinyu di suatu daerah rawan dengan tujuan agar persiapan secara dini dapat dilakukan guna mengantisipasi jika sewaktu-- waktu terjadi bencana.

\section{Kegiatan geowisata konsep pengenalan mitigasi}

Objek-objek warisan Bumi di dalam Geopark berpeluang menciptakan nilai ekonomi. Pengembangan ekonomi lokal melalui kegiatan pariwisata berbasis alam (geologi) atau geowisata merupakan salah satu pilihan. Penyelenggaraan kegiatan pariwisata Geopark secara berkelanjutan dimaknai sebagai kegiatan dan upaya penyeimbangan antara pembangunan ekonomi dengan usaha konservasi. Pengembangan kawasan Geopark melalui konsep pariwisata di aplikasikan sebagai instrumen pembangunan daerah secara berkelanjutan yang berdasarkan pada aspek konservasi, pendidikan, penumbuhan nilai ekonomi local. 




Gambar 6. Singkapan lembah ngarai sianok yang dikonsep sambal bergeowisata

\section{SIMPULAN}

Geopark Ngarai Sianok Maninjau masuk ke dalam zona lembahan patahan Sesar Sumatera (Sesar Semangko). Sesar Sumatera adalah sesar yang suatu saat dapat aktif kembali (reaktifasi) yang membuat lembah Ngarai Sianok. Penelitian ini dalam mendukung perwujudan pembangunan di Kawasan Geopark Ngarai Sianok Maninjau;

a. Analisis geologi mengidentifikasi bebatuan produk vulkanik mengisi daerah Ngarai Sianok dengan banyaknya ditemukan bukti -bukti patahan baik secara mayor maupun minor

b. Kawasan Ngarai Sianok dapat di jadikan kawasan terpadau secara realistis, objektif, terukur, dan dapat dilaksanakan dalam jangka waktu perencanaan dengan mengkonsep kawasan edukasi berbasis mitigasi dan lingkungan

c. Penelitian menjaga sinkronisasi antar program dalam satu kerangka program terpadu penelitian di objek Ngarai Sianok.

\section{DAFTAR PUSTAKA}

Ahman Sya, M. 2012. Geologi Pariwisata. Bandung: Universitas BSI Press.

Barber, A.J., Crow, M.J., dan Milson, J.S. (eds) .2005. Sumatera : Geology, Resources and Tektonic Evolution, Geological Society, Memoir, 31.

Bemmbelen, R.W. van. 1970. The geology of Indonesia. Martinus-Nijhoff, The Hague.

Dowling, R., \& Newsome, D. 2010. Chapter 1. Geotourism: A global activity. Global Geotourism Perspectives. Goodfellow London.

Fadhly, Ahmad. 2019. Geowisata Sumatera Barat, Dinas Pariwisata Sumatera Barat.

Oktariadi, oki. 2016. Warisan Geologi Ranah Minang. Sumatera Barat. 
Irzon, R., Sendjaja, P., Kurnia, Imtihanah \& Soebandrio, J. 2014. Kandungan Rare Earth Elements dalam Tailing Tambang Timah di Pulau Singkep. Jurnal Geologi dan Sumberdaya Mineral 15 (3) : 143-151.

Irzon, R. 2015a. Genesis Granit Muncung dari Pulau Lingga Berdasarkan Data Geokimia dan Mikroskopis. Jurnal Geologi dan Sumberdaya Mineral 16 (3) :141-149

Pulunggono, A.1985. The changing pattern of ideas on Sundaland within the last hundred years and its implication to oil exploration. In : Indonesia Petroleum Association, Proceeding of the 15th Annual Convention, Jakarta, 1986 I. 187-214.

Rosana, Mega F \& Prodjosumarto P. 1998. Pengantar praktikum Mineral Optik, UNPAD, Tidak diterbitkan

Rosidi, H.M.D., Tjokrosapoetro, S., Pendowo, B., Gafoer, S., dan Suharsono. 1996. Peta Geologi Lembar Painan dan Bagian Timur Lembar Muarasiberut, Pusat Penelitian dan Pengembangan Geologi, Bandung.

Setia G.Doddy. 1987. Mineral dan Batuan, Bandung: NOVA.

Silitonga, P. H. dan Kartowo. 1975. Peta Geologi Lembar Solok, Sumatra. Pusat Penelitian dan Pengembangan Geologi. 




Lampiran 1. Peta rawan bencana kawasan geopark ngarai sianok - maninjau 